\title{
The First Phylogenetic Analysis of Palpigradi (Arachnida)-The Most Enigmatic Arthropod Order
}

\section{Citation}

Gonzalo, Gilbert, McIntyre Erin, Christian Erhard, Espinasa Luis, Ferreira Rodrigo L., Francke Óscar F., Harvey Mark S., Isaia Marco, Kováč Lubomír, McCutchen Lynn, Souza Maysa F. V. R., and Zagmajster Maja. 2014. "The First Phylogenetic Analysis of Palpigradi (Arachnida) - The Most Enigmatic Arthropod Order." Invertebrate Systematics 28: 350-360. doi: 10.1071/IS13057

\section{Published Version}

doi:10.1071/IS13057

\section{Permanent link}

http://nrs.harvard.edu/urn-3:HUL.InstRepos:12313557

\section{Terms of Use}

This article was downloaded from Harvard University's DASH repository, and is made available under the terms and conditions applicable to Open Access Policy Articles, as set forth at http:// nrs.harvard.edu/urn-3:HUL.InstRepos:dash.current.terms-of-use\#OAP

\section{Share Your Story}

The Harvard community has made this article openly available.

Please share how this access benefits you. Submit a story.

\section{Accessibility}




\section{The first phylogenetic analysis of Palpigradi (Arachnida) - the most \\ 2 enigmatic arthropod order}

3 Gonzalo Giribet ${ }^{A, K}$, Erin Mclntyre $^{A}$, Erhard Christian ${ }^{B}$, Luis Espinasa $^{C}$, Rodrigo L. Ferreira ${ }^{D}$, Óscar F.

4 Francke ${ }^{E}$, Mark S. Harvey ${ }^{F}$, Marco Isaia $^{G}$, L'ubomìr Kovác $^{H}$, Lynn McCutchen', Maysa F. V. R.

5 Souza ${ }^{D}$ and Maja Zagmajster

6

7 A Museum of Comparative Zoology, Department of Organismic and Evolutionary Biology, Harvard

8 University, 26 Oxford Street, Cambridge, MA 02138, USA.

9 B Institut für Zoologie, Universität für Bodenkultur, Gregor-Mendel-Straße 33, 1180 Wien, Austria.

$10{ }^{\mathrm{C} S}$ School of Science, Marist College, 3399 North Road, Poughkeepsie, New York, USA.

$11{ }^{\mathrm{D}}$ Centro de Estudos em Biologia Subterrânea, Departamento de Biologia, Universidade Federal

12 de Lavras, Lavras, MG. CEP 37200-000, Brazil.

$13{ }^{E}$ Colección Nacional de Arácnidos, Instituto de Biologia, UNAM, Apartado Postal 70-153, C. P.

14 04510, Mexico, D. F., Mexico.

15 FDepartment of Terrestrial Zoology, Western Australian Museum, Locked Bag 49, Welshpool DC, 16 WA 6986, Australia.

$17{ }^{G}$ Dipartimento di Scienze della Vita e Biologia dei Sistemi, Università di Torino, Via Accademia 18 Albertina 13, 10123 Torino, Italy.

19 HDepartment of Zoology, Institute of Biology and Ecology, Faculty of Science, P. J. Šafárik

20 University, Moyzesova 11, 04001 Košice, Slovakia.

21 'Department of Biology, Kilgore College, 1100 Broadway, Kilgore, TX 75662, USA.

22 JSubBioLab, Department of Biology, Biotechnical Faculty, University of Ljubljana, Večna pot 111,

23 SI-1000 Ljubljana, Slovenia.

$24 \quad{ }^{K}$ Corresponding author. Email: ggiribet@g.harvard.edu 
25 Abstract. Palpigradi are a poorly understood group of delicate arachnids, often found in 26 caves or other subterranean habitats. Concomitantly, they have been neglected from a

27 phylogenetic point of view. Here we present the first molecular phylogeny of palpigrades based

28 on specimens collected in different subterranean habitats, both endogean (soil) and hypogean

29 (caves), from Australia, Africa, Europe, South America and North America. Analyses of two

30 nuclear ribosomal genes and $\mathrm{COI}$ under an array of methods and homology schemes found

31 monophyly of Palpigradi, Eukoeneniidae, and a division of Eukoeneniidae into four main clades,

32 three of which include samples from multiple continents. This supports either ancient vicariance

33 or long-range dispersal, two alternatives we cannot distinguish with the data at hand. In

34 addition, we show that our results are robust to homology scheme and analytical method,

35 encouraging further use of the markers employed in this study to continue drawing a broader

36 picture of palpigrade relationships.

37

38

39 Additional keywords: Arachnida, micro-whip scorpions, palpigrades, speleobiology,

40 biogeography. 
42 The arachnid order Palpigradi (micro-whip scorpions or palpigrades) is one of the smallest,

43 rarest and most neglected groups of terrestrial arthropods, and one of the last arachnid orders

44 to be discovered-it was first reported only in 1885 (Grassi and Calandruccio 1885). The first

45 photographs of living palpigrades did not appear published until the first decade of the 21st

46 century (Kováč et al. 2002; Beccaloni 2009). Additionally, only a handful of DNA sequence data

47 are available in GenBank; with only 64 sequences, 56 are for Prokoenenia wheeleri (Rucker,

48 1901), a species that was part of a multi-gene phylogeny of arthropods (Regier et al. 2010),

49 while the remaining eight sequences are unidentified specimens from three studies on

50 chelicerate phylogenetics (Giribet et al. 2002; Pepato et al. 2010; Arabi et al. 2012). Contrary to

51 this, one can find more DNA sequences for other small arachnid orders in GenBank: 105 for

52 Uropygi, 200 for Schizomida, 200 for Ricinulei, 251 for Amblypygi, and 502 for Pseudoscorpiones,

53 [checked on October 25th, 2013]. In addition, there are only 2 sequences available in the

54 Barcode of Life website (http://www.barcodinglife.org).

55 Palpigrades are delicate animals that walk sensing the substrate with what seems a nervous

56 behaviour of the first pair of walking legs, and use their unmodified palps for walking, unlike all

57 other arachnids (Fig. 1). While moving, most palpigrades keep the flagellum upward, moving it

58 laterally. Accordingly, it is possible that the uplifted flagellum is associated with perception of

59 the environment (Ferreira and Souza 2012). These small, depigmented and highly translucent

60 arachnids range in size from $0.65 \mathrm{~mm}$ in Eukoenenia grassii (Hansen, 1901) to $2.4 \mathrm{~mm}$ in the

61 "giant" E. draco (Peyerimhoff, 1906) from caves on the island of Majorca (Mayoral and Barranco

62 2013). Eukoenenia spelaea (Peyerimhoff, 1902) from Slovakia has recently been reported to

63 feed on heterotrophic Cyanobacteria (Smrž et al. 2013). The mode of sperm transfer in these

64 arachnids remains unknown.

65 The living members of the order are currently divided in two families, Eukoeneniidae

66 Petrunkevitch, 1955, with 4 genera and 85 named species, and Prokoeneniidae Condé, 1996,

67 with 2 genera and 7 named species (Harvey 2002; Prendini 2011; Souza and Ferreira 2013).

68 Eukoeneniidae includes the genera Allokoenenia Silvestri, 1913 (1 sp. from West Africa),

69 Eukoenenia Börner, 1901 (71 spp., on all continents under tropical and subtropical climate; in

70 temperate regions predominantly in caves), Koeneniodes Silvestri, 1913 (8 Palaeotropical spp.)

71 and Leptokoenenia Condé, 1965 (5 spp. in the Afrotropical, Neotropical and Palearctic regions). 
72 Prokoeneniidae includes the genera Prokoenenia Börner, 1901 (6 spp. in the Nearctic,

73 Neotropical and Oriental regions) and Triadokoenenia Condé, 1991 (1 sp. from Madagascar).

74 Further unnamed new species are known to us from various parts of the world.

75 The position of Palpigradi among the arachnid orders remains highly debated. The largest set of 76 data analysed to date places them as the sister group to Acariformes mites in a basal position

77 within arachnids, although without support (Regier et al. 2010). The most recent morphological

78 cladistic analysis of arachnid relationships leaves them mostly unresolved among the clades

79 Stomothecata, Haplocnemata, Pantetrapulmonata, and Acaromorpha (Shultz 2007). Earlier

80 studies combining morphology and a small set of molecular data placed Palpigradi as the sister

81 group of Ricinulei + Tetrapulmonata or as sister to Pycnogonida when fossils were considered,

82 although again, without significant clade support (Giribet et al. 2002); as sister to a clade

83 including Acari and Solifugae, based on the same two markers used in earlier studies (Pepato et

84 al. 2010); or in an unresolved position within arachnids (Arabi et al. 2012). Even less is known

85 about the internal relationships of the group, since no published study-molecular or

86 morphological-has yet incorporated information for more than one palpigrade species, and

87 only one unpublished masters thesis has explored palpigrade relationships cladistically, using

88 morphology (Montaño Moreno 2008).

89 To bridge this important gap in the knowledge of this arachnid order, although acknowledging

90 the difficulties in sampling and identification of these elusive animals, we obtained samples for

91 as many species of palpigrades as possible and from as many localities as possible with the aim

92 to obtain molecular DNA sequence data to generate a first hypothesis of internal palpigrade

93 relationships.

\section{$95 \quad$ Materials and Methods}

96 Taxon sampling

97 Palpigrades are difficult to obtain and identify, and success of field sampling differed among

98 regions included in the study. In Western Australia, many samples were collected indirectly in

99 caves and bore holes. In Brazil and Europe, they can be abundant in caves, where fresh

100 specimens have recently become available for inclusion in molecular studies. Additional samples 
were from soil samples in Australia, Italy and the USA. In addition to fresh material collected for

102 this study, older specimens were used, especially from the diverse cave systems in Brazil, where

103 several new species have been recently described (Souza and Ferreira 2010; Ferreira et al. 2011;

104 Souza and Ferreira 2011a; Souza and Ferreira 2011b; Souza and Ferreira 2012a; Souza and

105 Ferreira 2012b). While a recently collected specimen of Eukoenenia ferratilis Souza \& Ferreira,

1062011 amplified well for some of the studied markers, none of the six specimens of Allokoenenia

107 spp. and the two specimens of Leptokoenenia sp. collected from the caves yielded workable

108 DNA. We also obtained a relatively large collection of specimens from the Western Australian

109 bore holes from Barrow Island and the Pilbara, but these were collected from litter traps and

110 many specimens did not amplify or only yielded some amplicons. Some of these specimens are

111 probably related to the Western Australian endemic E. guzikae Barranco \& Harvey, 2008, but

112 unrelated to the more widespread species E. mirabilis (Grassi \& Calandruccio, 1885), also found

113 in Western Australia (Harvey et al. 2006; Barranco and Harvey 2008). A single specimen of

114 Prokoenenia wheeleri was obtained from the Austin area (Texas, USA), but amplified well for all

115 fragments attempted. In addition, we obtained samples of Eukoenenia mirabilis from Italy

116 (Christian et al. 2010) and Australia (Harvey et al. 2006), E. spelaea (Peyerimhoff, 1902) from

117 multiple localities in Slovenia and Slovakia (Kováč et al. 2002; Zagmajster and Kováč 2006; Král et

118 al. 2008). Italian samples also include E. bonadonai Condé, 1979 and E. strinatii Condé, 1977,

119 collected in caves. We also included specimens from multiple localities from the hanseni-

120 chilanga group of Eukoenenia from Mexico and the USA (Montaño-Moreno 2012). Additional

121 specimens come from Mexican caves and South Africa. Details on collecting localities are

122 available in Table 1 and in MCZBASE (http://mczbase.mcz.harvard.edu/SpecimenSearch.cfm).

123 Vouchers or additional specimens are deposited in the Museum of Comparative Zoology,

124 Harvard University (MCZ), and in the Western Australian Museum (WAM).

We included three species available in GenBank, one from South Africa sequenced by

126 Giribet et al. (2002), one from Brazil from Pepato et al. (2010), and one of unknown origin

127 published by Arabi et al. (2012). Here we added sequences from an additional South African

128 specimen from the same collection of that from Giribet et al. (2002), and a specimen of $E$.

129 ferratilis from Brazil, which was identical to the specimen reported by Pepato et al. (2010) as

130 Eukoenenia sp., and to which we refer to as $E$. cf. ferratilis in the present study. Outgroup taxa

131 were selected from GenBank (Table 2), mostly from previous studies on arthropod or arachnid

132 phylogeny using nuclear ribosomal genes (Giribet et al. 2002; Mallatt and Giribet 2006). 
135 Although we attempted to amplify and sequence five molecular markers typically used in other

136 analyses of arachnid systematics (e.g., Dimitrov et al. 2012; Giribet et al. 2012), the

137 mitochondrial 16S rRNA gene only amplified for Prokoenenia wheeleri and the nuclear protein-

138 encoding gene histone $\mathrm{H3}$, although amplified for several samples, did not produce clean reads.

139 We thus restricted our study to the two broadly available nuclear ribosomal genes, the

140 complete $18 \mathrm{~S}$ rRNA and ca. $2.2 \mathrm{~Kb}$ of $28 \mathrm{~S}$ rRNA, and the mitochondrial protein-encoding

141 cytochrome $c$ oxidase subunit I (COI hereafter) (as in Murienne et al. 2008), although the latter

142 gene only amplified for about a third of the specimens (Table 1). For two of the bore-hole

143 Western Australian specimens, poorly preserved, only the middle amplicon of 28S rRNA worked.

144 Total DNA was extracted from whole specimens or from the opisthosomal region using

145 Qiagen's DNEasy ${ }^{\circledR}$ tissue kit (Valencia, CA, USA). Although we were aiming to preserve the

146 digested carcass as a morphological voucher, it was completely digested and not recoverable.

147 Purified genomic DNA was used as a template for Polymerase chain reactions (PCR)

148 amplification. PCR, visualization by agarose gel electrophoresis, and direct sequencing were

149 conducted for most specimens as described in earlier work, e.g., Edgecombe and Giribet (2009).

150 Chromatograms obtained from the automatic sequencer were read and sequences assembled

151 using the sequence editing software Sequencher ${ }^{\mathrm{TM}}$ (Gene Codes Corporation, Ann Arbor, MI,

152 USA). Sequence data were edited in MacGDE (Linton 2005). The three genes were analysed as

153 follows:

154 18S rRNA: This marker was amplified in three amplicons $(a, b, c)$, as in previous studies

155 (Edgecombe and Giribet 2009; Giribet et al. 2010; Giribet et al. 2012). In the present study we

156 include 27 palpigrade specimens plus 8 outgroups, for a total of 1760-1771 bp per complete

157 sequence (up to $1805 \mathrm{bp}$ for one of the outgroups). From the 27 palpigrade sequences all but

158 three were complete; E. spelaea is missing fragment $a$ and the sample of Eukoenenia from South

159 Africa (DNA100456.2) is missing fragment $b$. For the direct optimization analyses the three

160 amplicons were treated as a single input file, containing 23 sequences, and divided into six

161 fragments. The three amplicons were concatenated for the static alignment analyses. 

Giribet and Shear (2010). The data set includes 29 palpigrade specimens plus 8 outgroups, for a total of 2,150 to $2,204 \mathrm{bp}$, with some length variation among species. These three fragments correspond to primer pairs $28 \mathrm{~S}$ rd1a-28D rd4b, 28Sa-28S rd5b, and $28 \mathrm{~S}$ rd4.8a-28S rd7b1. Some of the published sequences were amplified with a shorter fragment $b$, generated with primers 28Sa-28Sb (Whiting et al. 1997), and therefore fragment $b$ was divided into fragments $b 1$ and $b 2$ to accommodate these two amplicons. Fragment $a$ was available for 22 palpigrades and divided into three fragments, fragment $b$ for 29 palpigrades and three fragments, and fragment $c$ for 25 palpigrades and analysed as a single fragment. These were treated as three different amplicons for the dynamic homology analyses, but aligned together for the static homology approaches. COI: This widely used mitochondrial marker amplified for ten palpigrade terminals in a single amplicon using primers LCO-HCO, showing no length variation (654 bp analysed), plus one was available in GenBank. COI did not amplify for many individuals, perhaps due to major changes in this marker, as evidenced by the deletion of one amino acid with respect to the outgroups. Five outgroup sequences were obtained from GenBank, but these were 3 bp longer in all cases except for the pseudoscorpion. It was analysed as a single fragment; not pre-aligned due to the length difference with some outgroups.

Parsimony analyses were based on a direct optimization (DO) approach (Wheeler 1996) using POY v. 5.0 (Varón et al. 2012). Tree searches were performed using the timed search function in 184 POY, i.e., multiple cycles of (a) building Wagner trees, (b) subtree pruning and regrafting (SPR), and (c) tree bisection and reconnection (TBR), (d) ratcheting (Nixon 1999), and (e) tree-fusing (Goloboff 1999, 2002) [command: search (max_time:00:01:00, min_time:00:00:10,

187 hits:20, memory:gb:2) ]. For the individual partitions, timed searches of 1 hour were run on 1884 processors under six parameter sets, as in Giribet et al. (2012) (see Table 3). For the combined 189 analysis of the three markers we started with the same search strategy, giving the 28S rRNA 190 trees as input-as these contained all the taxa in the combined data set-, and the resulting 191 trees were given as input for a second round of analyses (sensitivity analysis tree fusing; SATF), 
as described by Giribet (2007), and continued until the tree lengths stabilised (Giribet et al. 2012). The optimal parameter set was estimated using the modified wILD metrics (Wheeler 1995; Sharma et al. 2011), as a proxy for the parameter set that minimizes overall incongruence among data partitions (Table 4). Nodal support for the optimal parameter set was estimated via jackknifing (250 replicates) with a probability of deletion of $\mathrm{e}^{-1}$ (Farris et al. 1996) using auto_sequence_partition, as discussed in earlier work (Giribet et al. 2012). alignments (MSA) inferred in MUSCLE v. 3.6 (Edgar 2004) through the EMBL-EBI server (http://www.ebi.ac.uk/Tools/msa/muscle/). We also used an implied alignment (IA) generated in POY (Wheeler 2003; Giribet 2005) for subsequent analyses based on static alignments, as recently explored by Giribet and Edgecombe (2013b) for a centipede data set. The MUSCLE alignments were conducted for each gene independently. The IA and MSA therefore were based on the same data (see length for each gene in Table 5). In order to evaluate the impact of the hypervariable regions in the data set, MSAs and IAs were subsequently trimmed with Gblocks v. 0.91b (Castresana 2000; Talavera and Castresana 2007) to cull positions of ambiguous homology (see length for each trimmed gene in Table 5). In the case of 28S, fragments $a$ and $b c$ were Gblocked separately, due to the larger proportion of missing data in the $a$ fragment, which otherwise would be deleted from the final $28 \mathrm{~S}$ alignment. These data sets are thus based on different data from their original sources and from each other, but the remaining data use the

\section{2 (Vaidya et al. 2011).}

Maximum likelihood analyses were conducted using RAxML ver. 7.2.7 (Stamatakis et al.

214 2008b) in the CIPRES server (Miller et al. 2010). For the searches, a unique General Time

215 Reversible (GTR) model of sequence evolution with corrections for a discrete gamma

216 distribution (GTR $+\Gamma$ ) was specified for each data partition, and 100 independent searches were

217 conducted. Nodal support was estimated via the rapid bootstrap algorithm (1000 replicates)

218 using the GTR-CAT model (Stamatakis et al. 2008a). Bootstrap resampling frequencies were

219 thereafter mapped onto the optimal tree from the independent searches. schemes, and/or amount of data, as follows: 
- Analysis 1. Direct optimization/dynamic homology under parsimony (full sensitivity analysis of 6 parameter sets) analysed in POY

- Analysis 2. Static homology from the implied alignment for the optimal parameter set under ML (analysed in RAxML)

\section{Results and Discussion}

233 All phylogenetic analyses yielded very similar results with respect to the ingroup relationships, 234 while the outgroup relationships were incongruent from analysis to analysis and unsupported 235 for the most part (Figs. 2 and 3). The latter was expected given the small amount of data and 236 outgroup taxa and the poor resolution in deep arachnid relationships in other studies (e.g., 237 Wheeler and Hayashi 1998; Giribet et al. 2002; Pepato et al. 2010; Regier et al. 2010). The 238 optimal parameter set under parsimony direct optimization was 3211 (where indel opening 239 costs 3 , indel extension 1 , transversions cost 2 and transitions cost 1 ; w ILD $=0.00913)$, with a 240 cost of 10,408 weighted steps (Fig. 2). Nearly all examined parameter sets concurred on the 241 topology of the optimal parameter set, with the exception of Eukoenenia spelaea IZ-19346 from 242 Slovenia, and the resolution of one of the Eukoenenia clades (see below). Likewise, the analyses 243 of the four data sets analysed under maximum likelihood were nearly identical, except for some 244 of the shallowest relationships. One of these trees, the one for the multiple sequence alignment 245 trimmed with Gblocks - the one that could be potentially the most different from the POY 246 analysis -is presented in Fig. 3, and it is virtually identical to the direct optimization tree. From 247 the 10 nodes depicted in Fig. 2 summarizing the six direct optimization and the four maximum 248 likelihood analyses, 5 were recovered in all analyses. Support values for these five nodes is high 249 for most analyses (jackknife values are lower by definition), with the exception of clades III and 250 IV in the DO analysis. Basically, nearly all analyses concur on the overall topology of the 251 palpigrade tree. 
All analyses show a basal dichotomy between Prokoenenia wheeleri (the only

253 Prokoeneniidae represented in our analyses) and the remaining samples, which we consider as

254 Eukoenenia for further discussion-even if some samples from GenBank or from the Australian

255 boreholes were not identified. Eukoenenia is divided into four main clades, indicated in Figures 2

256 and 3. Clade I includes E. florenciae from Slovakia, Brazil, and unidentified specimens probably

257 belonging to the same species from the USA and Mexico, and another species from a cave in

258 Guerrero, Mexico (IZ-128499). Clade II includes E. spelaea and E. s. hauseri Condé, 1974 from

259 Slovenia and Slovakia, and several additional samples from Slovenia and Italy, including $E$.

260 strinatii, E. bonadonai and E. austriaca (Hansen, 1926); E. spelaea IZ-19346 from Slovenia

261 clusters with these species in some analyses, but not all (Fig. 2). Clade III includes E. ferratilis

262 from Brazil, the specimens from the Australian bore holes, and an undescribed species from

263 Brazil (IZ-19345). Clade IV includes E. mirabilis from Australia and Italy, and unidentified

264 specimens from South Africa, plus a specimen from a cave in Chiapas, Mexico (IZ-136274) and a

265 GenBank specimen (JA-2011) of unknown origin. Clades I and II are supported in all analyses;

266 Clade III is supported in all analyses except for the DO analysis under parameter set 211; Clade

267 IV is unsupported in the ML analysis of the trimmed MSA. Eukoenenia spelaea IZ-19346 appears

268 as the sister group to Clade II under 4 analytical parameter sets in DO and in the untrimmed ML

269 analyses, both for the IA and for the MSA. The E. florenciae clade (Clade I) always forms the

270 sister group of the E. spelaea clade (Clade II), although E. spelaea IZ-19346 sometimes forms the

271 sister group of the $E$. florenciae clade. While the $E$. ferratilis clade (Clade III) often forms the

272 sister group to the E. mirabilis clade (Clade IV) (Figs. 2, 3), and is well supported in the

273 probabilistic analyses (97 to 100\% bootstrap support, depending on the analysis), under some

274 parameter sets Clade III is sister to the E. spelaea-E. florenciae clade (parameter sets 111, 211,

$275221,3221)$.

Irrespective of these small differences, our analyses show high congruence between alternative methods (parsimony and maximum likelihood) based on identical raw data with

278 different homology schemes (implied alignments versus multiple sequence alignments), or 279 different data sets (trimmed implied alignments and trimmed multiple sequence alignments).

280 There are very few cases with such consistency across weighting schemes, homology schemes, 281 and methodologies, but a recent case was documented for scutigeromorph centipedes (Giribet 282 and Edgecombe 2013b). In that case, the fossil record and denser sampling allowed for accurate 283 molecular dating and analyses of diversification of lineages through time, and it was suggested 
284 that the congruence across analyses was due to constant rates of diversification through more 285 than 400 million years of evolution in the group. We can only guess this for palpigrades, as the 286 fossil record for this group is rare, and a single Pliocene specimen is known (Rowland and Sissom 287 1980; Delclòs et al. 2008; Dunlop 2010), although the group must be much older in origin (see 288 for example Giribet and Edgecombe 2013a).

Phylogenetic analysis of the three molecular markers combined and for all analyses performed resolves into Prokoeneniidae (although represented by a single species) and Eukoeneniidae, supporting the monophyly of Eukoeneniidae-palpigrades without sternal opisthosomal vesicles (Condé 1996). We were, however, unable to obtain samples of Triadokoenenia or of additional Prokoenenia species, thus not being able to test the taxon Prokoeneniidae. Within Eukoeneniidae, the four main clades discussed above are supported in nearly all analyses. But species identifications in palpigrades do not seem straightforward. Within Clade I, the specimens of Eukoenenia from Texas (USA), the Mexican state of Yucatán, E. cf. florenciae from Brazil and E. florenciae from Slovakia show nearly identical COI sequences and identical nuclear ribosomal RNA sequences, suggesting that they may be conspecific (see Edgecombe and Giribet 2008; Vélez et al. 2012). In contrast, Clade II includes three lineages of the morphospecies E. spelaea. From these, two samples identified as E. spelaea and E. spelaea hauseri from Slovenia appear identical for the nuclear ribosomal genes (but did not amplify for COI).

Clade III includes the Western Australian samples and Eukoenenia ferratilis from the Iron caves of Minas Gerais (Brazil). Difficulties in amplifying the Australian samples and the lack of $\mathrm{COI}$ information for any of the members of the clade precludes us from understanding genetic variability within this clade of geographically distant species (both between the continents, but also among the Western Australian localities), although most analyses consistently resolve this clade of six individuals with reciprocal monophyly of the two geographic regions. unknown provenance sequenced by Arabi et al. (2012), a specimen from caves in Chiapas, and

311 the cosmopolitan E. mirabilis, including two specimens from Italy (identical for all markers) and

312 two putative members of this species from South Africa plus a sample of E. mirabilis from

313 Australia. While E. mirabilis has been suggested to be a synanthropic species originating in the

314 Mediterranean region with recent introductions to South Africa, Australia, Chile and 
315 Madagascar (Harvey et al. 2006), our limited data suggest a close relationship between one of

316 the South African samples and the Australian specimen, even in the absence of COI data, and

317 therefore suggesting changes in the nuclear ribosomal genes with respect to the Italian sample.

318 Further study of Gondwanan E. mirabilis and addition of circum-Mediterranean samples should

319 be undertaken to bring this matter to conclusion.

320 Given the sampling of this study it is still early to make any firm conclusions about 321 palpigrade relationships. We were not able to test for the monophyly of Prokoeneniidae, and 322 monophyly of Eukoenenia is not thoroughly tested either. Attempts to sequence Allokoenenia

323 and Leptokoenenia were unsuccessful, and we were unable to obtain specimens of the

324 Palaeotropical Koeneniodes and Triadokoenenia. Few studies have looked at variation among

325 palpigrade species, but Král et al. (2008) investigated the karyotypes of E. spelaea from Slovakia

326 and E. mirabilis, which appear in different clades in our study (Clades II and IV, respectively).

327 However, the karyotypes of both species showed no variation, both consisting of a low number

328 of tiny chromosomes that decrease gradually in size and a lack of morphologically differentiated

329 sex chromosomes, suggesting that molecular data may be more informative than karyotypic

330 data for separating species.

331 Morphologically, the characters used to differentiate Eukoenenia species are mostly

332 restricted to the number of lobules in the lateral organs or the number of setae in different body

333 regions, but the significance of these characters has not been tested phylogenetically-for

334 example, E. mirabilis and E. ferratilis are very similar morphologically with many somatic traits,

335 considered important for taxonomy, virtually identical (Souza and Ferreira 2011a). However,

336 these two species belong to different clades, reflecting that their differences in genital

337 morphology and chaetotaxy may be better systematic characters than the ones outlined above.

338 Our study thus provides a new framework for adding new sequences and testing the significance

339 of these characters. Additional samples and especially more genera must however be added

340 before we can attempt a taxonomic revision of the higher taxa in Palpigradi.

Conclusions

343 Palpigrades are a poorly understood group of tiny soil arthropods, often found exclusively in 344 caves, and have received little attention from a phylogenetic point of view. Here we were able 
345 to amass specimens from different environments (caves and soil) from Australia, Africa, Europe,

346 South America and North America with the aim of generating a molecular phylogenetic

347 hypothesis for the group. The difficulty in obtaining well-preserved material for molecular work

348 is reflected in the large number of specimens that did not yield DNA of enough quality for

349 sequencing, but we were able to propose the first phylogenetic hypothesis of the group based

350 on molecular data to find monophyly of Eukoeneniidae and its division into four main clades,

351 three of these including samples from multiple continents. Given the absence of denser

352 sampling and proper clock calibrations, our data cannot discern whether palpigrades are a very

353 old group that diversified prior to the breakup of Pangaea, or a group of animals that disperses

354 across large geographic distances, as suggested by some widespread species. Long-range

355 dispersal is however difficult to reconcile with the narrow ecological conditions and the facility

356 with which these animals desiccate once removed from their environments.

358 Acknowledgements

359 Julián Bueno-Villegas and Jesús A. Cruz-López helped with fieldwork in Yucatán; T. Delić and S.

360 Prevorčnik in Slovenia; P. Ĺuptáčik and A. Mock in Slovakia; L. Galli and M. Zinni provided

361 samples from Italy; J. Van der Schyff from South Africa; J. Christophoryová from Slovakia; staff

362 from the environmental companies Biota Environmental Sciences and Subterranean Ecology

363 provided samples from Western Australia. Gustavo Hormiga and Nikolaj Scharff kindly provided

364 comments that helped improve this article. This work has been supported by internal funds

365 from the Museum of Comparative Zoology and by NSF grant \#1144417 to G. G. and G. Hormiga

366 (Collaborative Research: ARTS: Taxonomy and systematics of selected Neotropical clades of

367 arachnids). 
Arabi, J., Judson, M. L., Deharveng, L., Lourenço, W. R., Cruaud, C., and Hassanin, A. (2012).

Barranco, P., and Harvey, M. S. (2008). The first indigenous palpigrade from Australia: a new Nucleotide composition of $\mathrm{CO} 1$ sequences in Chelicerata (Arthropoda): detecting new mitogenomic rearrangements. Journal of Molecular Evolution 74, 81-95. doi:10.1007/s00239-012-9490-7 species of Eukoenenia (Palpigradi : Eukoeneniidae). Invertebrate Systematics 22, 227 233.

Beccaloni, J. (2009). 'Arachnids.' (The Natural History Museum: London.)

Castresana, J. (2000). Selection of conserved blocks from multiple alignments for their use in phylogenetic analysis. Molecular Biology and Evolution 17, 540-552.

Christian, E., Capurro, M., and Galli, L. (2010). Phenology of two syntopic Eukoenenia species in a northern Italian forest soil (Arachnida: Palpigradi). Revue suisse de Zoologie 117, 829834.

Condé, B. (1996). Les palpigrades, 1885-1995: acquisitions et lacunes. Revue suisse de Zoologie hors série, 87-106.

Delclòs, X., Nei, A., Azar, D., Bechly, G., Dunlop, J. A., Engel, M. S., and Heads, S. W. (2008). The enigmatic Mesozoic insect taxon Chresmodidae (Polyneoptera): New palaeobiological and phylogenetic data, with the description of a new species from the Lower Cretaceous of Brazil. Neues Jahrbuch für Geologie und Palaontologie-Abhandlungen 247, 353-381.

Dimitrov, D., Lopardo, L., Giribet, G., Arnedo, M. A., Álvarez-Padilla, F., and Hormiga, G. (2012). Tangled in a sparse spider web: single origin of orb weavers and their spinning work unravelled by denser taxonomic sampling. Proceedings of the Royal Society B: Biological Sciences 279, 1341-1350. doi:10.1098/rspb.2011.2011

Dunlop, J. A. (2010). Geological history and phylogeny of Chelicerata. Arthropod Structure \& Development 39, 124-142. doi:10.1016/j.asd.2010.01.003 
Edgar, R. C. (2004). MUSCLE: multiple sequence alignment with high accuracy and high throughput. Nucleic Acids Research 32, 1792-1797. doi:10.1093/nar/gkh340

Edgecombe, G. D., and Giribet, G. (2008). A New Zealand species of the trans-Tasman centipede order Craterostigmomorpha (Arthropoda : Chilopoda) corroborated by molecular evidence. Invertebrate Systematics 22, 1-15. doi:10.1071/Is07036

Edgecombe, G. D., and Giribet, G. (2009). Phylogenetics of scutigeromorph centipedes (Myriapoda: Chilopoda) with implications for species delimitation and historical

Farris, J. S., Albert, V. A., Källersjö, M., Lipscomb, D., and Kluge, A. G. (1996). Parsimony jackknifing outperforms neighbor-joining. Cladistics 12, 99-124.

Ferreira, R. L., and Souza, M. F. V. R. (2012). Notes on the behavior of the advanced troglobite Eukoenenia maquinensis Souza \& Ferreira 2010 (Palpigradi: Eukoeneniidae) and its conservation status. Speleobiology Notes 4, 17-23.

Ferreira, R. L., Souza, M. F. V. R., Machado, E. O., and Brescovit, A. D. (2011). Description of a new Eukoenenia (Palpigradi: Eukoeneniidae) and Metagonia (Araneae: Pholcidae) from Brazilian caves, with notes on their ecological interactions. The Journal of Arachnology 39, 409-419. doi:10.1636/Ha11-03.1

Giribet, G. (2005). Generating implied alignments under direct optimization using POY. Cladistics Online 3, 341-356.

Giribet, G., and Edgecombe, G. D. (2013a). The Arthropoda: a phylogenetic framework. In 'Arthropod Biology and Evolution - Molecules, Development, Morphology'. (Eds A. Minelli, G. Boxshall and G. Fusco) pp. 17-40. (Springer: Berlin.) centipedes (Myriapoda : Chilopoda : Scutigeromorpha): dating the diversification of an 
ancient lineage of terrestrial arthropods. Invertebrate Systematics 27, 485-501. doi:10.1071/IS13019

424 Giribet, G., Edgecombe, G. D., Wheeler, W. C., and Babbitt, C. (2002). Phylogeny and systematic position of Opiliones: a combined analysis of chelicerate relationships using morphological and molecular data. Cladistics 18, 5-70.

Giribet, G., Sharma, P. P., Benavides, L. R., Boyer, S. L., Clouse, R. M., de Bivort, B. L., Dimitrov, D., Kawauchi, G. Y., Murienne, J. Y., and Schwendinger, P. J. (2012). Evolutionary and biogeographical history of an ancient and global group of arachnids (Arachnida:

Giribet, G., and Shear, W. A. (2010). The genus Siro Latreille, 1796 (Opiliones, Cyphophthalmi, Opiliones: Cyphophthalmi) with a new taxonomic arrangement. Biological Journal of the Linnean Society 105, 92-130. doi:10.1111/J.1095-8312.2011.01774.X

Giribet, G., Vogt, L., Pérez González, A., Sharma, P., and Kury, A. B. (2010). A multilocus approach to harvestman (Arachnida: Opiliones) phylogeny with emphasis on biogeography and the systematics of Laniatores. Cladistics 26, 408-437. doi:10.1111/j.10960031.2009.00296.x

Goloboff, P. A. (1999). Analyzing large data sets in reasonable times: solutions for composite optima. Cladistics 15, 415-428.

Goloboff, P. A. (2002). Techniques for analyzing large data sets. In 'Techniques in Molecular Systematics and Evolution'. (Eds R. DeSalle, G. Giribet and W. Wheeler) pp. 70-79. (Brikhäuser Verlag: Basel.)

445 Grassi, B., and Calandruccio, S. (1885). Intorno ad un nuovo aracnide artrogastro (Koenenia 446 mirabilis) che crediamo rappresentante d'un nuovo ordine (Microteliphonida). $447 \quad$ Naturalista Siciliano 4, 127-133, 162-169.

448 Harvey, M. S. (2002). The neglected cousins: What do we know about the smaller arachnid 449 orders? The Journal of Arachnology 30, 357-372. 
Harvey, M. S., Stáhlavsky, F., and Theron, P. D. (2006). The distribution of Eukoenenia mirabilis (Palpigradi: Eukoeneniidae): a widespread tramp. Records of the Western Australian Museum 23, 199-203.

Kováč, L., Mock, A., Ĺuptáčik, P., and Palacios-Vargas, J. G. (2002). Distribution of Eukoenenia spelaea (Peyerimhoff, 1902) (Arachnida, Palpigradida) in the Western Carpathians with remarks on its biology and behaviour. In 'Studies on Soil Fauna in Central Europe'. (Eds K. Tajovský, V. Balík and V. Pižl) pp. 93-99: České Budějovice.)

Král, J., Kováč, L., Št'ahlavský, F., Lonský, P., and L'uptácik, P. (2008). The first karyotype study in palpigrades, a primitive order of arachnids (Arachnida: Palpigradi). Genetica 134, 79-87.

Linton, E. W. (2005). MacGDE: Genetic Data Environment for MacOS X. (Software available at http://www.msu.edu/ lintone/macgde/)

Mallatt, J., and Giribet, G. (2006). Further use of nearly complete $28 \mathrm{~S}$ and $18 \mathrm{~S}$ rRNA genes to classify Ecdysozoa: 37 more arthropods and a kinorhynch. Molecular Phylogenetics and Evolution 40, 772-794. doi:10.1016/J.Ympev.2006.04.021

Mayoral, J. G., and Barranco, P. (2013). Rediscovery of the troglobious palpigrade Eukoenenia draco (Peyerimhoff 1906) (Palpigradi: Eukoeneniidae), with notes on the adaptations to a cave-dwelling life. Zootaxa 3635, 174-184. doi:10.11646/zootaxa.3635.2.5

Miller, M. A., Pfeiffer, W., and Schwartz, T. (2010). Creating the CIPRES Science Gateway for Inference of Large Phylogenetic Trees. In 'Proceedings of the Gateway Computing Environments Workshop (GCE)'. New Orleans pp. 1-8

Montaño Moreno, H. (2008). Revisión taxonómica de los palpígrados (Arachnida: Palpigradi) de México. Masters thesis, Universidad Nacional Autónoma de México.

Montaño-Moreno, H. (2012). Redescripción de Eukoenenia hanseni (Arachnida: Palpigradi) y descripción de una nueva especie de palpígrado de México. Revista Ibérica de Aracnología 20, 1-15.

Murienne, J., Harvey, M. S., and Giribet, G. (2008). First molecular phylogeny of the major clades of Pseudoscorpiones (Arthropoda: Chelicerata). Molecular Phylogenetics and Evolution 49, 170-184. doi:10.1016/j.ympev.2008.06.002 
478

Nixon, K. C. (1999). The Parsimony Ratchet, a new method for rapid parsimony analysis. Cladistics 15, 407-414.

Pepato, A. R., da Rocha, C. E., and Dunlop, J. A. (2010). Phylogenetic position of the acariform mites: sensitivity to homology assessment under total evidence. BMC Evolutionary Biology 10, 235. doi:10.1186/1471-2148-10-235

Prendini, L. (2011). Order Palpigradi Thorell, 1888 (In: Animal biodiversity: An outline of higherlevel classification and survey of taxonomic richness). Zootaxa 3148, 121.

Regier, J. C., Shultz, J. W., Zwick, A., Hussey, A., Ball, B., Wetzer, R., Martin, J. W., and Cunningham, C. W. (2010). Arthropod relationships revealed by phylogenomic analysis of nuclear protein-coding sequences. Nature 463, 1079-1083. doi:10.1038/nature08742

Rowland, J. M., and Sissom, W. (1980). Report on a fossil palpigrade from the Tertiary of Arizona, and a review of the morphology and systematics of the order (Arachnida, Palpigradida). The Journal of Arachnology 8, 69-86.

Sharma, P. P., Vahtera, V., Kawauchi, G. Y., and Giribet, G. (2011). Running wILD: The case for exploring mixed parameter sets in sensitivity analysis. Cladistics $\mathbf{2 7}, \mathbf{5 3 8 - 5 4 9 .}$ doi:10.1111/j.1096-0031.2010.00345.x

Shultz, J. W. (2007). A phylogenetic analysis of the arachnid orders based on morphological characters. Zoological Journal of the Linnean Society 150, 221-265.

Smrž, J., Kováč, Ĺ., Mikeš, J., and Lukešová, A. (2013). Microwhip scorpions (Palpigradi) feed on heterotrophic Cyanobacteria in Slovak caves - A curiosity among Arachnida. PLOS ONE 8, e75989. doi:10.1371/journal.pone.0075989

Souza, M. F. V. R., and Ferreira, R. L. (2010). Eukoenenia (Palpigradi: Eukoeneniidae) in Brazilian caves with the first troglobiotic palpigrade from South America. The Journal of Arachnology 38, 415-424.

Souza, M. F. V. R., and Ferreira, R. L. (2011a). A new species of Eukoenenia (Palpigradi: Eukoeneniidae) from Brazilian iron caves. Zootaxa 2886, 31-38. 
504 Souza, M. F. V. R., and Ferreira, R. L. (2011b). A new troglobitic Eukoenenia (Palpigradi:

505 Eukoeneniidae) from Brazil. Journal of Arachnology 39, 185-188. doi:10.1636/Ha10-43.1

506 Souza, M. F. V. R., and Ferreira, R. L. (2012a). Eukoenenia virgemdalapa (Palpigradi:

$507 \quad$ Eukoeneniidae): a new troglobitic palpigrade from Brazil. Zootaxa 3295, 59-64.

508 Souza, M. F. V. R., and Ferreira, R. L. (2012b). A new highly troglomorphic species of Eukoenenia

509 (Palpigradi: Eukoeneniidae) from tropical Brazil. The Journal of Arachnology 40, 151-158.

510 Souza, M. F. V. R., and Ferreira, R. L. (2013). Two new species of the enigmatic Leptokoenenia (Eukoeneniidae: Palpigradi) from Brazil: First record of the genus outside intertidal environments. PLOS ONE 8, e77840. doi:10.1371/journal.pone.0077840

513 Stamatakis, A., Hoover, P., and Rougemont, J. (2008a). A rapid bootstrap algorithm for the 514 RAxML Web servers. Systematic Biology 57, 758-771. doi:10.1080/10635150802429642

515 Stamatakis, A. P., Meier, H., and Ludwig, T. (2008b). RAxML: A parallel program for phylogenetic $516 \quad$ tree inference.

517 Talavera, G., and Castresana, J. (2007). Improvement of phylogenies after removing divergent 518 and ambiguously aligned blocks from protein sequence alignments. Systematic Biology $519 \quad 56,564-577$. doi:10.1080/10635150701472164

520 Vaidya, G., Lohman, D. J., and Meier, R. (2011). SequenceMatrix: concatenation software for the 521 fast assembly of multi-gene datasets with character set and codon information. Cladistics 27, 171-180. doi:10.1111/j.1096-0031.2010.00329.x

523 Varón, A., Lucaroni, N., Hong, L., and Wheeler, W. C. (2012). POY 5.0.0. (American Museum of $524 \quad$ Natural History. http://research.amnh.org/scicomp: New York)

525 Vélez, S., Mesibov, R., and Giribet, G. (2012). Biogeography in a continental island: population 526 structure of the relict endemic centipede Craterostigmus tasmanianus (Chilopoda, 527 Craterostigmomorpha) in Tasmania using 16S rRNA and COI. Journal of Heredity 103, 80-

529 Wheeler, W. C. (1995). Sequence alignment, parameter sensitivity, and the phylogenetic analysis 530 of molecular data. Systematic Biology 44, 321-331. 
531 Wheeler, W. (1996). Optimization alignment: the end of multiple sequence alignment in 532 phylogenetics? Cladistics 12, 1-9.

533 Wheeler, W. C. (2003). Implied alignment: a synapomorphy-based multiple-sequence alignment 534 method and its use in cladogram search. Cladistics 19, 261-268.

535 Wheeler, W. C., and Hayashi, C. Y. (1998). The phylogeny of the extant chelicerate orders.

$536 \quad$ Cladistics 14, 173-192.

537 Whiting, M. F., Carpenter, J. M., Wheeler, Q. D., and Wheeler, W. C. (1997). The Strepsiptera 538 problem: phylogeny of the holometabolous insect orders inferred from $18 \mathrm{~S}$ and $28 \mathrm{~S}$ 539 ribosomal DNA sequences and morphology. Systematic Biology 46, 1-68.

540 Zagmajster, M., and Kováč, Ĺ. (2006). Distribution of palpigrades (Arachnida, Palpigradi) in 541 Slovenia with a new record of Eukoenenia austriaca (Hansen, 1926). Natura Sloveniae 8, $542 \quad 23-31$. 
544 Fig. 1. Photographs of (A) Eukoenenia spelaea, Ardovská Cave (Slovak Karst, Slovakia),

545 photographed by L'. Kováč \& V. Kóňa; (B) Prokoenenia wheeleri, Austin (Texas, USA),

546 photographed by L. McCutchen; (C) Eukoenenia mirabilis, flagellum, segments 1 to 10; (D)

547 Eukoenenia bonadonai, male genital lobes; (E) E. bonadonai, female genital lobes; (F) E.

548 bonadonai, mouth cone and chelicerae (C-D photographed by E. Christian).

549

550 Fig. 2. Left: Optimal tree at 10,408 weighted steps obtained from the direct optimization

551 analysis under parameter set 3211 of the combined analysis of the three genes. Numbers on

552 branches indicate jackknife support values. Navajo rugs are shown in selected nodes; Black

553 square indicates monophyly, white square non-monophyly. Specific parameter sets or analyses

554 indicated in the figure. Numerals indicate parameter set under parsimony direct optimization; IA

555 (ML analysis using implied alignment under parameter set 3211); IAg (Idem, Gblocked); MSA

556 (ML analysis of the MUSCLE multiple sequence alignment); MSAg (Idem, Gblocked). Clades I to

$557 \quad$ IV are indicated.

558

559 Fig. 3. Optimal maximum likelihood tree $(-\operatorname{Ln} L=-24955.690470)$ of the combined data set using

560 the MUSCLE multiple sequence alignment trimmed with Gblocks. Numbers on nodes indicate

561 bootstrap support values. 
Table 1. Palpigrade specimens, accession numbers, collecting information and amplified loci with GenBank accession numbers

IZ: Department of Invertebrate Zoology, Museum of Comparative Zoology, Cambridge; DNA: MCZ DNA collection; WAM: Western Australian Museum, Perth; MNHN: Muséum national d'histoire Naturelle, Paris. A dash (-) indicates a missing amplicon. New sequences are KF823823 to KF823883

\begin{tabular}{|c|c|c|c|c|c|c|c|c|c|c|}
\hline & & & & & 18S rRNA & & & 28S rRNA & & COI \\
\hline & MCZ No. & & Country & $a$ & $\boldsymbol{b}$ & $c$ & a & $\boldsymbol{b}$ & $c$ & \\
\hline Prokoenenia wheeleri & IZ-134477 & DNA107078 & Texas, USA & KF823823 & KF823823 & KF823823 & KF823848 & KF823848 & KF823848 & KF823874 \\
\hline Eukoenenia austriaca & IZ-19349 & - & Slovenia & KF823824 & KF823824 & KF823824 & KF823849 & KF823849 & KF823849 & - \\
\hline Eukoenenia bonadonai & IZ-19340 & - & Italy & KF823825 & KF823825 & KF823825 & KF823850 & KF823850 & KF823850 & - \\
\hline Eukoenenia ferratilis & IZ-127609 & - & Brazil & KF823826 & KF823826 & KF823826 & KF823851 & KF823851 & KF823851 & - \\
\hline Eukoenenia cf. ferratilis & - & GenBank & & HM070336 & HM070336 & HM070336 & HM070299 & HM070299 & HM070299 & - \\
\hline Eukoenenia florenciae & IZ-19351 & - & Slovakia & KF823827 & KF823827 & KF823827 & KF823852 & KF823852 & KF823852 & KF823875 \\
\hline Eukoenenia cf. florenciae & IZ-19343 & - & Brazil & KF823828 & KF823828 & KF823828 & KF823853 & KF823853 & KF823853 & - \\
\hline Eukoenenia mirabilis & IZ-127901 & - & Italy & KF823829 & KF823829 & KF823829 & KF823854 & KF823854 & KF823854 & KF823876 \\
\hline Eukoenenia mirabilis & IZ-127902 & - & Italy & KF823830 & KF823830 & KF823830 & KF823855 & KF823855 & KF823855 & KF823877 \\
\hline Eukoenenia mirabilis & IZ-16117 & - & Australia & KF823831 & KF823831 & KF823831 & KF823856 & KF823856 & KF823856 & - \\
\hline Eukoenenia spelaea & IZ-135126 & DNA106786 & Slovakia & - & KF823832 & KF823832 & KF823857 & KF823857 & KF823857 & - \\
\hline Eukoenenia spelaea & IZ-19346 & - & Slovenia & KF823833 & KF823833 & KF823833 & KF823858 & KF823858 & KF823858 & KF823878 \\
\hline Eukoenenia spelaea & IZ-19347 & - & Slovenia & KF823834 & KF823834 & KF823834 & KF823859 & KF823859 & KF823859 & - \\
\hline $\begin{array}{l}\text { Eukoenenia spelaea } \\
\text { hauseri }\end{array}$ & IZ-19348 & - & Slovenia & KF823835 & KF823835 & KF823835 & KF823860 & KF823860 & KF823860 & - \\
\hline Eukoenenia strinatii & IZ-19341 & - & Italy & KF823836 & KF823836 & KF823836 & KF823861 & KF823861 & KF823861 & - \\
\hline Eukoenenia sp. & IZ-19350 & - & Slovenia & KF823837 & KF823837 & KF823837 & KF823862 & KF823862 & KF823862 & KF823879 \\
\hline
\end{tabular}




\begin{tabular}{|c|c|c|c|c|c|c|c|c|c|c|}
\hline Eukoenenia sp. & - & DNA100456.1 & South Africa & AF207648 & AF207648 & AF207648 & - & AF207653 & - & - \\
\hline Eukoenenia sp. & - & DNA100456.2 & South Africa & KF823838 & - & KF823839 & - & KF823863 & - & - \\
\hline Eukoenenia sp. & IZ-134549 & DNA107079 & USA & KF823840 & KF823840 & KF823840 & KF823864 & KF823864 & KF823864 & KF823880 \\
\hline Eukoenenia sp. & IZ-127598.1 & - & Mexico & KF823841 & KF823841 & KF823841 & KF823865 & KF823865 & KF823865 & KF823881 \\
\hline Eukoenenia sp. & IZ-127598.2 & - & Mexico & KF823842 & KF823842 & KF823842 & KF823866 & KF823866 & KF823866 & KF823882 \\
\hline Eukoenenia sp. & IZ-128499 & - & Mexico & KF823843 & KF823843 & KF823843 & KF823867 & KF823867 & KF823867 & KF823883 \\
\hline Eukoenenia sp. & IZ-136274 & - & Mexico & KF823844 & - & KF823844 & KF823868 & KF823868 & KF823868 & - \\
\hline Eukoenenia sp. & IZ-127636 & WAM T81111 & Australia & - & - & - & - & KF823869 & - & - \\
\hline Eukoenenia sp. & IZ-127639 & $\begin{array}{c}\text { WAM } \\
\text { T116012 }\end{array}$ & Australia & KF823845 & KF823845 & KF823845 & - & KF823870 & KF823870 & - \\
\hline Eukoenenia sp. & IZ-127640 & $\begin{array}{c}\text { WAM } \\
\text { T111422 }\end{array}$ & Australia & - & - & - & - & KF823871 & - & - \\
\hline Eukoenenia sp. & IZ-127643 & - & Australia & KF823846 & KF823846 & KF823846 & - & KF823872 & KF823872 & - \\
\hline Eukoenenia sp.n. & IZ-19345 & - & Brazil & KF823847 & KF823847 & KF823847 & - & KF823873 & KF823873 & - \\
\hline Palpigradi sp. & - & MNHN-JAA76 & & JN018286.1 & JN018286.1 & JN018286.1 & JN018383.1 & JN018383.1 & JN018383.1 & JN018169.1 \\
\hline
\end{tabular}


Table 2. Outgroup sampling with GenBank accession numbers

$\begin{array}{lllll} & & \text { 18S rRNA } & \text { 28S rRNA } & \text { COI } \\ \text { Anoplodactylus portus } & \text { Pycnogonida } & \text { AY859551 } & \text { AY859550 } & \text { GQ912859 } \\ \text { Limulus polyphemus } & \text { Xiphosura } & \text { U91490 } & \text { AF212167 } & \text { AF216203 } \\ \text { Pandinus imperator } & \text { Scorpiones } & \text { AY210831 } & \text { AY210830 } & \text { AY156582 } \\ \text { Metasiro americanus } & \text { Opiliones } & \text { DQ825542 } & \text { DQ825595 } & \text { DQ825645 } \\ \text { Calocheiridius termitophilus } & \text { Pseudoscorpiones } & \text { AY859559 } & \text { AY859558 } & \text { EU559544 } \\ \text { Dermacentor sp. } & \text { Acari } & \text { Z74480 } & \text { AY859582 } & - \\ \text { Eremobates sp. } & \text { Solifugae } & \text { AY859573 } & \text { AY859572 } & - \\ \text { Mastigoproctus giganteus } & \text { Uropygi } & \text { AF005446 } & \text { AY859587 } & \text { JN018215 }\end{array}$


Table 3. Result of the POY timed searches (search) and improvement after each round of SATF for the six explored parameter sets

\begin{tabular}{|l|c|c|c|}
\hline & $\mathbf{1}$ & SATF2 & SATF3 \\
\hline $\mathbf{1 1 1}$ & 6520 & 6520 & 6520 \\
\hline $\mathbf{1 2 1}$ & 10076 & 10076 & 10076 \\
\hline $\mathbf{2 1 1}$ & 7543 & 7543 & 7543 \\
\hline $\mathbf{2 2 1}$ & 11851 & 11851 & 11851 \\
\hline $\mathbf{3 2 1 1}$ & 10408 & 10408 & 10408 \\
\hline $\mathbf{3 2 2 1}$ & 13526 & 13526 & 13526 \\
\hline
\end{tabular}


Table 4. Number of weighted steps for each data partition, the combination of them (MOL) and wILD value

The optimal parameter set is indicated in italics

\begin{tabular}{|l|r|r|r|r|r|}
\hline & $\mathbf{1 8 S}$ & $\mathbf{2 8 S}$ & COI & MOL & wILD \\
\hline $\mathbf{1 1 1}$ & 1125 & 3967 & 1354 & 6520 & 0.01135 \\
\hline $\mathbf{1 2 1}$ & 1655 & 6272 & 2051 & 10076 & 0.00973 \\
\hline $\mathbf{2 1 1}$ & 1246 & 4840 & 1381 & 7543 & 0.01008 \\
\hline $\mathbf{2 2 1}$ & 1867 & 7780 & 2080 & 11851 & 0.01046 \\
\hline $\mathbf{3 2 1 1}$ & 1704 & 6535 & 2074 & 10408 & 0.00913 \\
\hline $\mathbf{3 2 2 1}$ & 2314 & 8305 & 2777 & 13526 & 0.00961 \\
\hline
\end{tabular}


Table 5. Length of each data partition (28S rRNA is divided into three amplicons) and total length of alignment

IA (121) is for implied alignment under parameter set 121 ; IA+Gb is for implied alignment trimmed with Gblocks; Muscle is for MUSCLE multiple sequence alignment; Muscle+Gb is for multiple sequence alignment trimmed with Gblocks

$\begin{array}{lrrrrr} & \mathbf{1 8 S} & \mathbf{2 8 S a} & \mathbf{2 8 S b c} & \text { COI } & \text { TOTAL } \\ \text { Unaligned } & 1760-1805 & 832-873 & 1265-1347 & 654-657 & \\ \text { IA (3211) } & 1860 & 1323 & 1555 & 669 & 5407 \\ \text { IA+Gb } & 1676 & 378 & 1162 & 626 & 3842 \\ \text { Muscle } & 1818 & 1046 & 1409 & 663 & 4936 \\ \text { Muscle+Gb } & 1695 & 609 & 1212 & 636 & 4152\end{array}$

